\title{
Chapter 2
}

\section{Role of some emerging agro-chemicals in groundwater contamination}

\section{Ifra Ashraf1,", Tanzeel Khan', Nowsheeba Rashid², Shazia Ramzan ${ }^{3}$ and Noureen Khurshid1}

\section{Chapter contents}

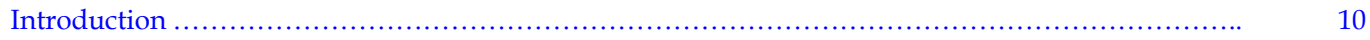

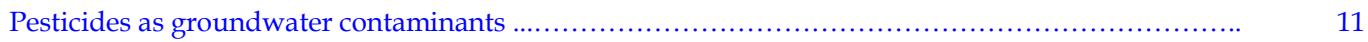

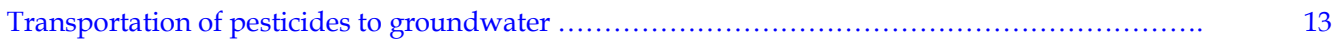

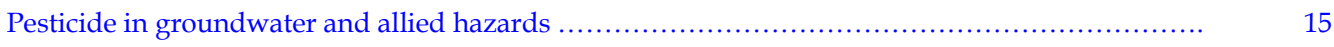

Antagonistic effects of pesticide (herbicide) application on non-target plants .................... 16

Health-based guideline values for pesticide residues in potable water . ........................ 17

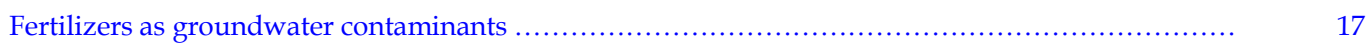

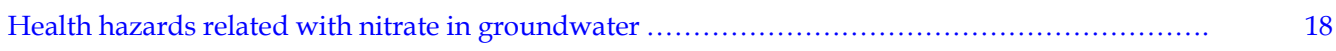

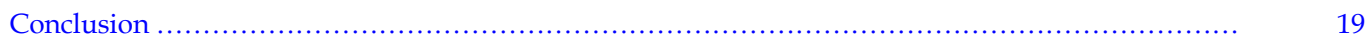

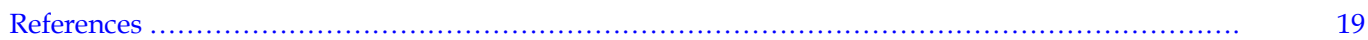

\begin{abstract}
The escalating food demand to feed the incessantly mounting world population has put a lot of pressure on our already over burdened agricultural system. The urge to cultivate more food has made us reliant on supplementary use of agrochemicals like pesticides and fertilizers. Unsystematic use of agrochemicals has amplified the production of crops but it has also posed rigorous hazards to environment because it has contaminated the natural resources, like groundwater. The groundwater resources are vulnerable to pollution, the occurrence of pesticide residues in the groundwater resources (water located beneath the soil's surface) constitutes a global problem worldwide, especially in the least developed countries where the use of plant protection products is very high. For the development of microbial originated pesticides, which

(国 Ifra Ashraf, Email: iframir3@gmail.com

${ }^{1}$ College of Agricultural Engineering and Technology, SKUAST-K, Shalimar, INDIA

2 Amity Institute of Food Technology, Amity University Noida, Uttar Pradesh, INDIA

3 Department of Geography and Regional Development, University of Kashmir, Srinagar, J\&K, INDIA


are valuable, dependable and have a low environmental risk there seems to be a great potential. Also, novel application techniques, such as exactitude band spraying, can decrease the dose, which can be an extremely successful way to minimize transport and emanation and in addition can avoid a build-up of confrontation in target organisms. Enhanced formulations will besides be required to decrease off-target deposition, recover withholding on target, and augment uptake and translocation. The book chapter deals with the contributory approach of agrochemicals to contamination of ground water.

Keywords: Biomagnification, Degradation, Fertilizers, Groundwater, Pesticides

\section{Introduction}

Agrochemical, also referred to as agrichemical, a contracted form of agricultural chemical, is a phrase used for the different chemical products employed as a part of farming. Generally, agrichemical implies pesticides which include herbicides, fungicides, insecticides and nematicides (chemicals for killing round-worms). Agrochemicals also include synthetic fertilizers, hormones and other chemical growth drivers, and concentrated stores of raw animal manure (Pimentel et al., 2004). The burgeoning population growth is continuously heightening the food demand which in turn has put a lot of pressure on our already over-burdened agrarian system. The prerequisite to produce more food has pressurized us to rely on extended use of agrochemicals. The agrochemicals have been playing a key role for fostering the agrarian productivity to meet the expanding population's needs since a long time. But now their use has caught an eye on account of their relentlessly irrational and non-judicious use. Nevertheless, there is no conflict of idea with regards to their utility in boosting the agricultural productivity and safeguarding the supply of agricultural produces meeting the food, health and other necessities of the animal and human population. Adsorption, degradation, and movement processes are key processes to know the persistence of a pesticide and its ability to contaminate groundwater bodies (Kumar et al., 2018). The main factors affecting the fate of pesticides are their physicochemical properties (water solubility, vapour pressure, adsorption coefficient, etc.), soil characteristics (texture, organic matter content, etc.), site (hydrogeological conditions), and management practices (method of application and dosage).

Haphazard consumption of agrochemicals has instigated austere vulnerabilities to environment on a whole but in particular groundwater resource (Khanna and Gupta, 2018). Groundwater is the water that is present in porous soils and rocks below the surface of earth or the water present in aquifers beneath the land surface. So far groundwater source of water is deliberated as the most reliable source of unpolluted water, playing a pivotal role in upholding hydrological cycle owing to its direct link with the surface water. The prominence of groundwater for subsistence of humans can't be disregarded because it is the chief source of palatable water in both rural as well as urban India. Moreover, it is an eminent source of water for industrial and agricultural sector. 
It is well-known that agriculture is the sole biggest consumer of freshwater sources, expending globally an average of $70 \%$ of all surface water supplies (Pimentel et al., 2004). The water consumed for irrigation purpose is returned back to surface/ground water reserves except the water lost in the process of evapotranspiration. The exigency of water is incessantly intensifying in India owing to many reasons; greater amount of water is required to satiate the need of over-populated country, unpredictable precipitation patterns are compelling agriculture to rely on irrigation and swift industrialization is also incumbent upon greater consumption of water. The state of affairs of water emergency is further worsened due to contamination of the fresh water reserves present below and above ground. Faulty agrarian practices like over-use of agrochemicals play a principal role in soiling and poisoning the ground water.

Agriculture is both source as well as victim of groundwater pollution. It becomes a causal agent triggering groundwater through the flux of chemical pollutants and sediments into groundwater system. Contrarily, when the same contaminated groundwater is tapped for irrigation purpose, it contaminates crops and transfers its negative effects in the ecosystem. Moreover, once groundwater gets soiled with noxious chemicals, it may take several years to detoxify or clear the contaminants. In this chapter, the negative impacts of these agrochemicals on the groundwater will be discussed. It has been found that the pollution of groundwater caused due to the use of agro-chemicals is mainly attributed to pesticides and fertilisers; hence the effect of these two agrochemicals on environs will be reviewed.

\section{Pesticides as groundwater contaminants}

A pesticide also referred to as plant protection product is any "substance intended for preventing, destroying, repelling, or mitigating any pest in crops either before or after harvest to prevent deterioration during storage or transport" (Pérez-Lucas et al., 2018). The pesticide term acts an umbrella for all the formulations including herbicides, fungicides, insecticides, rodenticides, insect growth regulators, defoliants, molluscicides, antimicrobials, and household disinfectants used to eradicate some pests (Ozkara et al., 2016). Pesticide products consist of both active as well as inert ingredients. Active ingredients are employed to control diseases, pests, and weeds, whereas inert ingredients also referred to as adjuvants (dyes, stabilizers, etc.) are imperative for product usability and performance. Around 850 different pesticide formulations are in use (Cheremisinoff and Rosenfeld, 2010), although the restraint of public health vulnerabilities also lingers to be an important field of application. In last few decades, the use of pesticides has tremendously increased improving the quality and quantity of food on one hand, while as enhanced use has caused substantial pollution of terrestrial ecosystems and poisoning human foods (Carvalho, 2017).

Pesticides can be categorized according to their mode or period of action, their target or their chemical composition (Drum, 1980). The most widely known is the classification based on target. For instance, insecticides are the pesticides that aim killing insects, rodenticides target rodents, 
and herbicides target plants. Likewise the others are fungicides, miticides, acaricides, bactericides, molluscicides, virucides and avicides. The other classification based on the way the pesticides interact with the plants categorises them into two classes: nonsystemic and systemic. Nonsystemic pesticides are those that don't substantially enter plant tissues and thus not transported within the plant vascular system. Contrarily, systemic pesticides are those that effectually penetrate plant tissues and get transported within the plant vascular system to cause the anticipated effect. The classification based on chemical nature and active ingredients is the most useful one while considering the effect of pesticides on environment because it helps in streamlining the application rates while taking into consideration the physical and chemical properties of individual pesticides. In accord with the chemical properties, pesticides can be divided broadly into seven types, comprising of organochlorines, organophosphorus, pyrethroids, carbamates, anilins, amides, and azotic heterocyclic compounds (Ozkara et al., 2016).

Table 2.1. Examples of different pesticides (Adopted from Jayaraj et al., 2016).

\begin{tabular}{|c|c|}
\hline Pesticide type & Examples \\
\hline \multirow[t]{5}{*}{ Organochlorines } & DDT (Dichlorodiphenyltrichloroethane), Eldrin, Dieldrin, Dicofol, \\
\hline & Toxaphene, HCH (Hexachlorocyclohexane), DDD \\
\hline & (Dichlorodiphenyldichloroethane), Lindane, Chlorobenziate, \\
\hline & Methoxychloro Aldrin, BHC, Chlordane, Endosufan, Heptaclor, \\
\hline & Isodrin, Isobenzan, Chloro propylate \\
\hline \multirow[t]{4}{*}{ Organophosphates } & Dimefox, Methyl Parathion, Mipafox, Bidrin, Ronnel, Enitrothion, \\
\hline & Fenthion, Phorate, Abate, Dichlorovas, Caumphos, Phosphomidon, \\
\hline & Diptrex, Oxydemeton-methyl, Dimethoate, Demetox, Malathion, \\
\hline & Trichlorofan \\
\hline \multirow[t]{6}{*}{ Carbamates } & Methyl: \\
\hline & Dimetilan, Carbaryl, Isolan, Prupoxur, Carbanolate, Carbofuran, \\
\hline & $\begin{array}{l}\text { Dimethan, Pyrolan, Aldicarb, Aminocarb } \\
\text { Thio: }\end{array}$ \\
\hline & Diallate, Vernolate, Monilate, Pebulate, Trillate, Butylate, Thiourea, \\
\hline & $\begin{array}{l}\text { Cycloate } \\
\text { Dithio: }\end{array}$ \\
\hline & Thiram, Methan, Amoban, Ferban, Zineb, Maneb, Naban, Dithane \\
\hline Pyrethroids & $\begin{array}{l}\text { M- 45, Ziram Polyran } \\
\text { Bonthrin, Allethrin, Tetramethrin, Dimethrin, Furethrin, Ptrethrin, }\end{array}$ \\
\hline Amide pesticides & $\begin{array}{l}\text { Alphamethrin, Cyclethrin, Fenevelerate, Cypermethrin, Decamethrin } \\
\text { Butachlor, Acetochlor, Metolachlor }\end{array}$ \\
\hline Anilins and & Pendimethalin, Trifluralin \\
\hline $\begin{array}{l}\text { dinitroaniline } \\
\text { Nitrogen-containing }\end{array}$ & Triazole, Forimidazole \\
\hline heterocyclic pesticides & \\
\hline
\end{tabular}


The examples of each group are presented in Table 2.1.

- Organochlorine pesticides are organic compounds having five or more chlorine atoms. They were the first artificial organic pesticides that were expended in agriculture and public health. These pesticides in general possess the stable chemical structure, eventually persist and get hoarded in the environment, hence belonging to the class of persistent organic pollutants (POPs). Most of them are broadly exploited as insecticides for the curbing wide-ranging insects.

- Organophosphates are another form of highly noxious pesticides that are esters of phosphoric acid. The synthetic organophosphates were recognised initially as warfare materials during the epoch of Second World War. Since then, they have been exploited in diverse fields like agriculture, cosmetics, industry, medicine, etc. They have the potential for inactivating the acetylcholine esterase (AChE) enzyme.

- Carbamates are organic pesticides derived from carbamic acid $\left(\mathrm{NH}_{2} \mathrm{COOH}\right)$, which are akin to organophosphates in having the potential of incapacitating the enzyme acetylcholine esterase (AChE). Howbeit, the carbamates differ from organophosphates in their mode of action such that carbamates are species specific and their cholinesterase inhibition is reversible.

- Pyrethroids and pyrethrins are are artificial analogues isolated from the flowers of pyrethrums (Chrysanthemum Coccineum and Chrysanthemum cinerariaefolium). They were spotted in the 1980s to impersonate the insecticidal venture of the natural pyrethrum. They are greatly recognized for their quick bowling down effect against insects, low mammalian toxicity and facile biodegradation.

- Amide pesticides are systemic pesticides which enter the food chain thereby affecting the nutrient cycling. Acetochlor, metolachlor, and butachlor are the amide pesticides which are widely used in recent years.

- Anilins and dinitroaniline pesticides are the widely used group of pesticides. For example, Trifluralin and pendimethalin.

- Nitrogen-containing heterocyclic pesticides, especially triazole and forimidazole heterocyclic chemicals, have turned into the hotspot for novel pesticide synthesis. Since the last decade, almost $70 \%$ of the newly developed pesticides belong to this class (Zheng et al., 2016).

\section{Transportation of pesticides to groundwater}

Every single pesticide present in groundwater, and majority residues there in surface water penetrate into the soil largely by overspills and recharge. There are mostly two major routes through which pesticides penetrate into the soil: discharge from granulates openly functional to the soil (López-Pérez et al., 2006) and spray drift to soil throughout floral management plus wash-off from treated flora (Rial Otero et al., 2003) (Figure 2.1). Nonpoint sources of pesticides originating from areas where they were applied- rather than point sources such as wastewater 


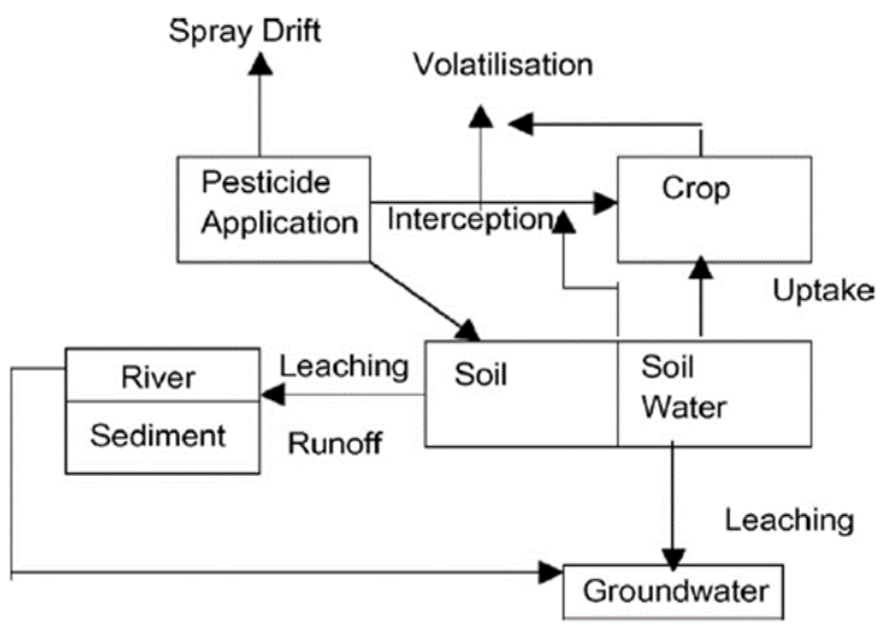

Figure 2.1. Routes of a pesticide directed to a crop (Source: Arias-Estévez et al., 2008).

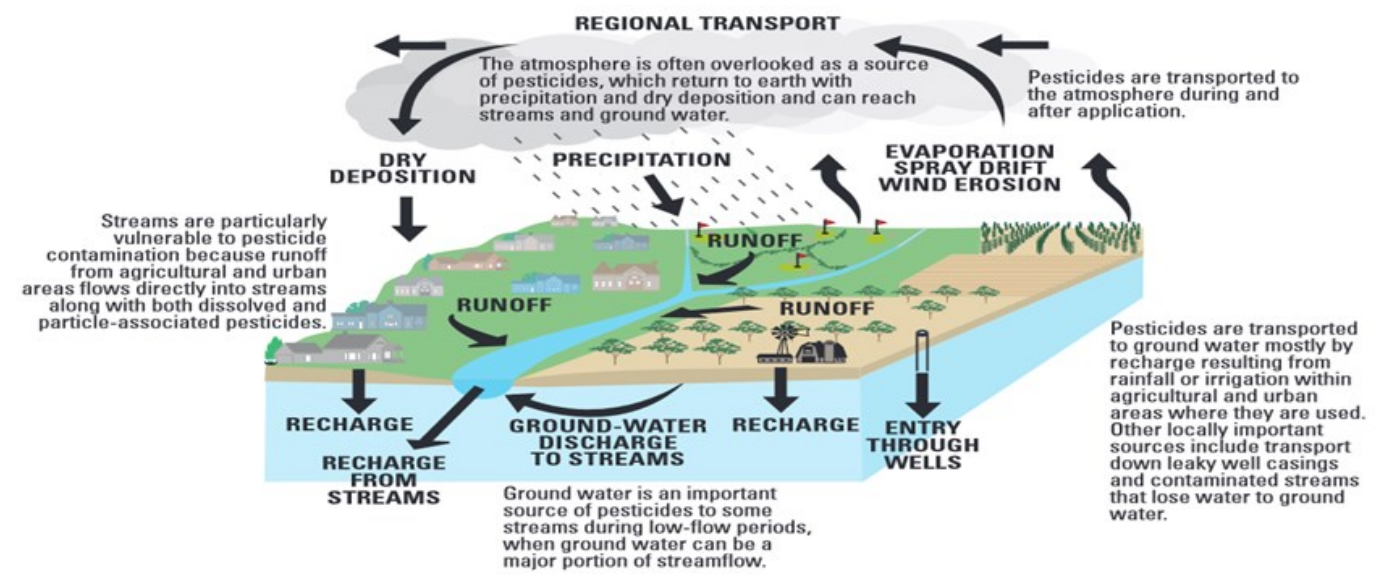

Figure 2.2. Movement of pesticides in environment (Source: Gilliom et al., 2006).

discharges- are the most widespread causes of pesticides occurrence in streams and groundwater. The movement of pesticides in an ecosystem is illustrated in Figure 2.2. The major primary approach of pesticides to reach groundwater is the water that permeates through the soil and exceeds all the way through the fundamental unsaturated region to the water table. As with watercourses, the majority of pesticide transfer to ground water is motivated by rainwater or irrigation when alone or both upshots in ground-water revitalization. Transport in ground-water is dissimilar from transportation in streams as only dissolved types of pesticides as well as degradates (novel compounds produced by the conversion of a pesticide by chemical or biological reactions) travel considerable distances with ground water. Soil and aquifer materials largely retain the particle bound compounds. Moreover, transportation of pesticide compounds 
into and inside ground water to a large extent is less knowable in comparison to transport in streams since the surge of ground water is significantly slower and extra intricate than the surge of stream water. Pesticides as well as their degradates can travel voluntarily to ground water via portable zones, such as worm holes, or permeable sediments, cracks, however a fraction of pesticide compounds is reserved in stationary zones inside the subsurface where current is minimal. Pesticide compounds that are reserved in stationary zones can be unconstrained steadily to ground water by dissemination and consequent leaching, at times protracted following application.

Greatly as a soap-filled mop ought to be frequently washed and squeezed before all of the soap is separated, the soil operates as a basin from which pesticides and their degradates prolong to leach following submission. As a consequence, pesticides may perhaps be present in ground water much earlier than expected subsequent to application (for the reason of brisk movement through transportable zones), and also for comprehensive epoch afterward (because of regular discharge from immobile zones).

\section{Pesticide in groundwater and allied hazards}

Development of agriculture is strongly associated to exercise of pesticides. The utilization of pesticides has assisted in thwarting the damages originated by pest attacks and has enhanced the manufacturing prospective of crops, although these surplus amounts are escaping down to ground water thus creating its pollution. Pesticide contamination in ground water is exceedingly very much associated to perseverance of pesticides in soil. Perhaps, it has been approximated that less than $0.1 \%$ of the insect repellent applied to crops in reality contact the target pest; the rest go into the environment pointlessly, polluting the soil, water and air, where it can toxin or else negatively distress non target organisms (Pimentel and Levitan, 1986). In addition, a lot of pesticides can persevere for extended periods in an ecosystem, organochlorine insecticides, for example, were still evident in surface waters 20 years subsequent to their employment had been prohibited (Larson et al., 1997); and formerly an unrelenting pesticide has penetrated the food chain, it can go through "biomagnification", i.e., accretion in the body tissues of organisms, where it may attain absorption many times privileged than in the adjacent environment.

Capability of a pesticide to acquire absorption chooses whether it will trickle down to ground water or not. The pesticides having minimal adsorption or absorption capacity for surface of soil will percolate downwards to ground water and will direct to its contamination. Groundwater pollution on account of pesticides is a global glitch. As stated by the U.S. Geological Survey, at least 143 different pesticides and 21 transformation products have been discovered in ground water, including pesticides from every single major chemical class (Aktar et al., 2009). Numeral reports are documented on the subject of the ground water contamination via remainders of pesticides. Pesticides source severe health risk to existing systems as they are hastily soluble in fat and they can mount up in objective organisms. The risks associated with consumption of groundwater contaminated due to pesticides can be grouped into two categories: 
Hazards owing to highly noxious pesticides: Organochlorines, organophosphates, and carbamates are three cohorts of traditional highly toxic pesticides. Organochlorine insecticides operate as nervous system disruptors causing seizures and paralysis of the insect and its ultimate fatality. These pesticides can cause severe endocrine disarray in mammals, fish, and birds; therefore the majority of them have been prohibited in agriculture globally. The organophosphates pesticides reduce the acetylcholinesterase enzyme, responsible for hydrolyses acetylcholine in the nervous system of a lot of species, together with humans (Frasco et al., 2006), hence impairing the nervous system. Even though they are simpler to be ruined than organochlorines, organophosphate pesticide remains is major threat to the ecosystem as well as food industry as their severe toxicities are permanent. Numerous populaces are exposed to pesticides professionally, and pesticide self-poisoning is a chief civic health crisis. Yearly, 3 million cases of severe poisoning have been accounted from pesticide contact, ensuing in the demises of 250 to 370000 people each year (Marrs, 1993). Hence, the practice of organophosphates has been constrained or prohibited globally.

Hazards occurred because of low toxic pesticides: The soon after developed anilines, amides, pyrethroids, and azotic heterocyclic complexs are normally less toxic. The pyrethroids are nonpersistent sodium conduit modulators and are little noxious than carbamates and organophosphates to mammals. For that reason, the practice of pyrethroids has been augmented significantly in the last 30 years. Sadly, pyrethroids are extremely poisonous to marine organisms such as fish, mollusks, and arthropods (Koureas et al., 2012). Butachlor can persevere in the surroundings for up to 10 weeks, and what's still inferior is that butachlor and metolachlor have been recognized as mutagens. The Trifluralin and pendimethalin pesticides demonstrate elevated toxicity to marine organisms and they can harm the thyroid gland and liver. Therefore, these two aniline herbicides have been prohibited in a lot of European countries.

\section{Antagonistic effects of pesticide (herbicide) application on non-target plants}

Herbicides are devised to eradicate the unwanted plants from the main crops. So, there is no surprise in realising that they have potential to damage or kill the desired crops if applied directly or indirectly while tapping contaminated groundwater. Additionally, the sub-lethal effects are caused due to pesticide exposure on plants. Phenoxy herbicides, including 2,4-D, have potential of injuring the shrubs and trees in vicinity if they coast on the leaves. Some herbicides like glyphosate are capable of sternly reducing seed quality, and increasing the disease vulnerability of particular plants. The pesticides can also affect the beneficial microbial count in soil and insects necessary for overall health of soil and plants. For instance, Glyphosate can reduce the development and activity of free-living nitrogen-fixing bacteria in the soil (Biswas et al., 2014). Hence, it can be impressed upon that the plants not only can suffer directly at the hands of the pesticides, but can also encounter indirect repercussions of pesticide treatment when soil microorganisms and beneficial insects are maltreated. 
Health-based guideline values for pesticide residues in potable water

Younes and Galal-Gorchev (2000) elucidated the existing WHO approach for assessing health-based recommendations (or guideline values, GVs) for pesticide residues in drinking water. GVs were computed from $1 \%$ of the tolerable daily intake (TDI) for the highly toxic pesticides like organochlorines and from 10\% TDI for rest. The GV for potentially oncogenic pesticides is grounded on modelling approach and is related with an estimated upper-bound excess lifetime risk of 10-5. The guideline values arrived upon by Younes and Galal-Gorchev (2010) are shown in Table 2.2.

\section{Fertilizers as groundwater contaminants}

Disproportionate exploitation of nitrogenous fertilizers within agriculture has been one of the principal causes of soaring levels of nitrate in groundwater. Nitrogen is applied in two forms viz. ammonium $\left(\mathrm{NH}_{4}{ }^{+}\right)$and amide $\left(\mathrm{NH}_{2}^{-}\right)$, apart from nitrate, which produce nitrate in soil system through mineralization, which is comparatively swift in tropical and subtropical soils. Because of its elevated solubility in water and stumpy withholding by soil particles, nitrate is prone to discharge to the subsoil layers and eventually to the groundwater, if not engaged up by plants or denitrified to $\mathrm{N}_{2} \mathrm{O}$ and $\mathrm{N}_{2}$.

Table 2.2. Guideline values based on health developed by WHO for pesticide remainders in drinking water (Source: Younes and Galal-Gorchev, 2000).

\begin{tabular}{llll}
\hline Pesticides & $\begin{array}{l}\text { Guideline } \\
\text { value, } \boldsymbol{\mu g} / \mathbf{l}\end{array}$ & Pesticides & $\begin{array}{l}\text { Guideline } \\
\text { value, } \mathbf{\mu g} / \mathbf{l}\end{array}$ \\
\hline Bentazone & 300 & Aldicarb & 10 \\
Metolachlor & 10 & Atrazine & 2 \\
Isoproturon & 9 & Carbofuran & 7 \\
Propanil & 20 & 2,4-D & 30 \\
Pendimethalin & 20 & Cyanazine & 0.6 \\
Simazine & 2 & 2,4-DB & 90 \\
Pyridate & 100 & Chlordane & 0.2 \\
Alachlor & 20 & Aldrin/dieldrin & 0.03 \\
Chlortoluron & 30 & DDT & 2 \\
1,2-Dibromo-3- chloropro- & 1 & Dichlorprop & 20 \\
pane & & & \\
1,3-Dichloropropene & 20 & Diquat & 10 \\
Methoxychlor & 20 & Fenoprop & 9 \\
EDB & $0.4-15$ & Trifluralin & 20 \\
Heptachlor + epoxide & 0.03 & Hexachlorobenzene & 1 \\
& & & \\
Isoproturon & 9 & Mecoprop & 10 \\
MCPA & 2 & Lindane & 2 \\
Methoxychlor & 20 & Molinate & 6 \\
2,4,5-T & 9 & Terbuthylazine & 7 \\
\hline
\end{tabular}


Table 2.3. Tolerance limits of $\mathrm{NO}_{3}$ in potable water recommended by different nations and organizations (Source: Majumdar and Gupta, 2000).

\begin{tabular}{|c|c|c|}
\hline Country/Organization & $\begin{array}{l}\text { Concentration as } \\
\mathrm{NO}_{3}-\mathrm{N}(\mathrm{mg} / \mathrm{l})\end{array}$ & $\begin{array}{l}\text { Concentration as } \\
\mathrm{NO}_{3}(\mathrm{mg} / \mathrm{l})\end{array}$ \\
\hline "US Environmental Protection & 10 & 45 \\
\hline \multicolumn{3}{|l|}{ Agency } \\
\hline${ }^{*} \mathrm{WHO}$ & 10 & 45 \\
\hline *ICMR (India) & 10 & 45 \\
\hline *Poland & 10 & 45 \\
\hline${ }^{*}$ Canada & 10 & 45 \\
\hline${ }^{*} \mathrm{EEC}^{\mathrm{a}}$ & 11.30 & 50 \\
\hline *Bulgaria & 6.7 & 30 \\
\hline Denmark & 11.3 & 50 \\
\hline Belgium & 11.3 & 50 \\
\hline Hungary & 9.0 & 40 \\
\hline Finland & 6.8 & 30 \\
\hline USA & 10 & 45 \\
\hline \multirow[t]{2}{*}{ UK } & $11.3^{b}$ & 50 \\
\hline & $22.6^{c}$ & 100 \\
\hline
\end{tabular}

The pace of discharge is directed by the characteristics of soil and quantity of water there in the soil system (Majumdar and Gupta, 2000). The influx of nitrate to groundwater can be improved by superficial groundwater table; undue submission of nitrogenous fertilizers, manures and irrigation; and profuse rainfall. The former imperative sources causative of high quantity of nitrate to groundwater are barnyards, livestock feeding, septic tanks, animal and human contamination. Within and around areas of towering urbanization and industrialization, public and industrial wilds may add soaring levels of nitrate to the groundwater. As soon as the nitrate loaded groundwater is propelled out and utilized for drinking, it sources lot of health muddles in humans. Diverse associations and countries have positioned valued standards for $\mathrm{NO}_{3}$ in potable water (Table 2.3), to maintain public health from the dangers linked with high concentration of nitrate.

\section{Health hazards related with nitrate in groundwater}

Nitrate as such is not a problem but it becomes a problem only when it is transformed into nitrite in the human body and results in a disease like Methaemoglobinemia (also referred to as Blue Baby Disease or Blue Baby Syndrome), gastric cancer and some other health disorders in humans. Nitrite produced from nitrate in drinking water enters the bloodstream mainly through the upper gastrointestinal tract. The nitrite in bloodstream causes oxidation of haemoglobin to methaemoglobin, a Fe (III) compound with diminished oxygen carrying capacity owing to higher oxidation state of Fe making it incapable to bind with oxygen. Consequently, the oxygen carrying capacity of bloods gets depleted and oxygen shortage causes the cyanosis, i.e., skin colour turns 
into blue. The babies are susceptible to this disease more as compared to adults owing to their high fluid intake, hence the name blue baby disease. Nitrate, can react with different organic compounds and result in the formation of carcinogenic compounds including nitrosamines and nitrosamides as a result of nitrosation reactions in the stomach. These carcinogenic nitroso compounds are considered to take part in the aetiology of some forms of cancers in humans. A carcinogen namely dimethylnitrosamine is produced in the stomach from dimethylamine present in gastric juice. Nonetheless the formation reaction of dimethylnitrosamine is slow in stomach and quantities produced may be low (Majumdar and Gupta, 2000), which can dormant the cancer for 20-30 years (Bockman and Granli, 1991). The high nitrate intake in drinking water has also reported to cause other health disorders namely hypertension (Malberg et al., 1978), nonHodgkin's lymphoma (Weisenburger, 1991) and enhanced infant mortality.

\section{Conclusion}

Ground water is one of the prized natural resources, but it is under continuous threat owing to the prolonged application of the agrochemicals. The application of the agrochemicals is the need of an hour so as to feed the burgeoning population, control the pest attack on plants and eradicate the weeds. However, their application is done at a significant cost, which warrants a threat to almost every sphere of ecosystem; groundwater being the delicate of all because it's cleansing needs years to return back it to its original clean state. In the light of the above cited facts, it is manifested that the agricultural activities serve as a potential pollutant of groundwater. Therefore, strategies need to be made to minimise the drift of excessive agrochemicals from agrarian fields to ground water. The agrochemicals should be applied and handled in accordance with the regulations and recommendations levied by different organisations which aim to minimise the negative impacts of these chemicals on the human health and environment. The agrochemical whose traces persist in the groundwater for years should be completely banned globally.

\section{References}

Aktar, W., Sengupta, D. and Chowdhury, A. (2009). Impact of pesticides use in agriculture: their benefits and hazards. Interdisciplinary Toxicology, 2(1): 1-12.

Arias-Estévez, M., López-Periago, E., Martínez-Carballo, E., Simal-Gándara, J., Mejuto, J. C., and García-Río, L. (2008). The mobility and degradation of pesticides in soils and the pollution of groundwater resources. Agriculture, Ecosystems $\mathcal{E}$ Environment, 123(4): 247-260.

Biswas, S.K., Rahman, S., Kobir, S.M.A., Ferdous, T. and Banu, N.A. (2014). A review on impact of agrochemicals on human health and environment: Bangladesh perspective. Plant Environment Development, 3(2): 31-35.

Bockman, O. C., Granli, T. (1991). Human health aspects of nitrate intake from food and water. In Chemistry. Agriculture and the Environment (Ed. ML Richardson). The Royal Society of Chemistry, Cambridge, pp. 373.

Carvalho, F.P. (2017). Pesticides, environment, and food safety. Food and Energy Security, 6(2): 48-60.

Cheremisinoff, N.P. and Rosenfeld, P. (2010). Handbook of Pollution Prevention and Cleaner Production Vol. 3: Best Practices in the Agrochemical Industry. William Andrew. pp. 20-33. 
Drum, C. (1980). Soil Chemistry of Pesticides. PPG Industries, Inc. USA.

Frasco, M.F., Fournier, D., Carvalho, F. and Guilhermino, L. (2006). Cholinesterase from the common prawn (Palaemon serra$t u s)$ eyes: catalytic properties and sensitivity to organophosphate and carbamate compounds. Aquatic toxicology, 77(4): 412-421.

Gilliom, R.J., Barbash, J.E., Crawford, C.G., Hamilton, P.A., Martin, J.D., Nakagaki, N., Nowell, L.H., Scott, J.C., Stackelberg, P.E., Thelin, G.P. and Wolock, D.M. (2006). Pesticides in the nation's streams and ground water, 1992-2001 (No. 1291 ). US Geological Survey.

Jayaraj, R., Megha, P. and Sreedev, P. (2016). Organochlorine pesticides, their toxic effects on living organisms and their fate in the environment. Interdisciplinary Toxicology, 9(3-4): 90-100.

Khanna, R. and Gupta, S. (2018). Agrochemicals as a potential cause of ground water pollution: A review. International Journal of Chemical Studies. 6(3): 985-990.

Koureas, M., Tsakalof, A., Tsatsakis, A. and Hadjichristodoulou, C. (2012). Systematic review of biomonitoring studies to determine the association between exposure to organophosphorus and pyrethroid insecticides and human health outcomes. Toxicology Letters, 210(2): 155-168.

Kumar, V., Chauhan, R.K., Srivastava, S., Singh, J. and Kumar, P. (2018). Contamination, enrichment and translocation of heavy metals in certain leafy vegetables grown in composite effluent irrigated soil. Archives of Agriculture and Environmental Science, 3(3): 252-260.

Larson, S.J., Capel, P.D. and Majewski, M.S. (1997). Pesticides in surface waters - distribution, trends, and governing factors. In: Gilliom, R.J. (Ed.), Series of Pesticides in Hydrologic System, Vol. 3. Ann Arbor Press, Chelsea, Michigan.

López-Pérez, G.C., Arias-Estévez, M., López-Periago, E., Soto-González, B., Cancho-Grande, B. and Simal-Gándara, J. (2006). Dynamics of pesticides in potato crops. Journal of Agricultural and Food Chemistry, 54(5): 1797-1803.

Majumdar, D. and Gupta, N. (2000). Nitrate pollution of groundwater and associated human health disorders. Indian Journal of Environmental Health, 42(1): 28-39.

Malberg, J.W., Savage, E.P. and Osteryoung, J. (1978). Nitrates in drinking water and the early onset of hypertension. Environmental Pollution, 15(2): 155-160.

Marrs, T.C. (1993). Organophosphate poisoning. Pharmacology \& Therapeutics, 58: 51-66.

Ozkara, A., Akyıl, D. and Konuk, M. (2016). Pesticides, environmental pollution, and health. In Environmental Health RiskHazardous Factors to Living Species. IntechOpen. pp. 1-4.

Pérez-Lucas, G., Vela, N., El Aatik, A. and Navarro, S. (2018). Environmental Risk of Groundwater Pollution by Pesticide Leaching through the Soil Profile. In Pesticides, Anthropogenic Activities and the Health of our Environment. IntechOpen.

Pimentel, D., Berger, B., Filiberto, D., Newton, M., Wolfe, B., Karabinakis, E., Clark, S., Poon, E., Abbett, E. and Nandagopal, S. (2004). Water resources: agricultural and environmental issues. BioScience, 54(10): 909-918.

Pimentel, D., Levitan, L. (1986). Pesticides: amounts applied and amounts reaching pests. Bioscience, 36: 86-91.

Rial Otero, R., Cancho Grande, B., Arias Estévez, M., López Periago, E. and Simal Gándara, J. (2003). Procedure for the measurement of soil inputs of plant-protection agents washed off through vineyard canopy by rainfall. Journal of Agricultural and Food Chemistry, 51(17): 5041-5046.

Weisenburger, D.D. (1991). Potential health consequences of ground-water contamination by nitrates in Nebraska. In Nitrate Contamination, Springer, Berlin, Heidelberg. pp. 309-315

Younes, M. and Galal-Gorchev, H. (2000). Pesticides in drinking water-a case study. Food and Chemical Toxicology, 38: S87S90.

Zheng, S., Chen, B., Qiu, X., Chen, M., Ma, Z. and Yu, X. (2016). Distribution and risk assessment of 82 pesticides in Jiulong River and estuary in South China. Chemosphere, 144: 1177-1192.

$* * * * * * *$

Cite this chapter as: Ashraf, I. Khan, T., Rashid, N. Ramzan, S. and Khurshid, N. (2019). Role of some emerging agro-chemicals in groundwater contamination. In: Kumar, V., Kumar, R., Singh, J. and Kumar, P. (eds) Contaminants in Agriculture and Environment: Health Risks and Remediation, Volume 1, Agro Environ Media, Haridwar, India, pp. 9-20, https://doi.org/10.26832/AESA-2019-CAE-0168-02 